\title{
Exploring factors affecting students' continued Wiki use for individual and collaborative learning: An extended UTAUT perspective
}

\author{
Hsiu-Ping Yueh, Jo-Yi Huang and Chueh Chang \\ National Taiwan University, Taiwan
}

\begin{abstract}
The purpose of this study was to investigate what factors affect students' adaptation and continued use of a Wiki system for collaborative writing tasks through an extension of the Unified Theory of Acceptance and Use of Technology (UTAUT). This study was conducted in a general education course in a university in northern Taiwan. Data were collected from surveys of 103 students after their continued writing on the CourseWiki system for one semester. With structural equation model (SEM) analysis, results from this study partially confirm that, in the UTAUT model, factors of social influence have direct and significant effects on students' actual usage of the Wiki system. Moreover, students' actual use of the Wiki influences their intention of future use. This study successfully applies the extended UTAUT model and tests the predictive power in determining students' acceptance of a Wiki system in terms of their actual use and their behavioural intentions of future use. It further provides suggestions for future research and practice, and should contribute to theoretical understanding as well as practical application of learning technology in post-secondary teaching.
\end{abstract}

\section{Introduction}

Computer-supported collaborative learning (CSCL) is concerned with the study of how people can learn together with the help of computers (Stahl, Koschmann \& Suthers, 2006). Researchers have long been interested in understanding the interplay of learning and technology in CSCL, with a special interest in exploring how computers can bring students together to learn collaboratively in small groups and learning communities. Some researchers have focused on the nature of collaborative learning under the condition of computer support (Stahl, 2005; Suthers, 2006); others have focused on the technology, or on design and the study of fundamental social technology (Koschmann, 2002), and still others have focused on the students' evaluations of the computer-supported collaborative learning system, since success in applying computer-supported learning depends on learners' loyalty (Chiu \& Wang, 2008; Dewiyanti, Brand-Gruwel, Jochems \& Broers, 2007). Eales, Hall and Bannon (2002) compared CSCL studies in different settings and argued that motivation, an essential issue in successful computer-supported collaborative learning, was often overlooked. Stahl et al. (2006) contend that CSCL research should identify the unique advantage of computational media and how such media influence students to learn collaboratively.

Wikis are collaborative websites comprised of the collective works of multiple authors. On a Wiki, any community member can freely edit, delete, and modify content (Engstrom \& Jewett, 2007), and together, all contributors gain knowledge through these collaborative efforts. The Wiki paradigm offers opportunities for sharing and ease of collaboration amongst Web community users. Users may create specific sets of group members with access to sites for specific projects, providing an excellent collaborative environment for the users (Boulos, Maramba \& Wheeler, 2006). Executing a collaborative writing task on a Wiki facilitates peer assessment, which could raise students' awareness of their work and improve its quality (Xiao \& Lucking, 2008). Wikis also support meta-conversation by keeping the original versions of the revised or edited pages in an archive, where the entire production process of a work can be traced.

Recently, a few studies have confirmed that Wikis can be used as a teaching aid (Parker \& Chao, 2007) and a learning aid (Kimmerle, Moskaliuk \& Cress, 2011) when applied in classrooms during collaborative works by the students. As few studies have explored the factors that influence students the most when they use Wikis to accomplish their collaborative tasks, Wei, Maust, Barrick, Cuddihy and Spyridaki (2005) suggested that more studies be conducted to empirically determine how to support 
collaborative work on Wikis, and to determine what factors may affect students' willingness to adopt and continue to use Wikis for collaborative writing in educational contexts in the future.

\section{Purpose of the study}

Information system researchers have long worked to understand people's acceptance of computational technology (Davis, 1989; Davis, 1993). One's initial use and continuance of use are important factors in the success of information systems (Venkatesh, Morris, Davis \& Davis, 2003). Furthermore, while users collaborate for learning online, the collaboration itself and the technology they use may also influence their exploration and understanding.

This study investigates key factors that influence students' online collaborative writing behaviour on Wikis. Through clearly determining the importance of the success factors contributing to the group user's acceptance of a Wiki system in a collaborative learning environment, the current study may contribute to the understanding of the primary issues in predicting user's acceptance for continuous use for the future (Venkatesh, 2000). The Unified Theory of Acceptance and Use of Technology (UTAUT), proposed by Venkatesh et al. (2003), explains how people adopt and accept the use of a technology in the workplace. A modified Extended UTAUT model is used in this study as a model to test student use of a Wiki system. The specific research objectives of the study were: (a) to apply the model and test the predictive power of an extended UTAUT in determining students' acceptance of a Wiki system in terms of their actual use and behavioural intentions of future use; (b) to investigate both the direct and indirect effects of these determinants on intent to continue using the Wiki system, including performance expectancy, effort expectancy, social influence, and facilitating conditions; and (c) to provide insights into how Wikis could support collaborative learning.

\section{Collaborative learning in Web 2.0 Era}

The theoretical framework of collaborative learning is underpinned by the theory of constructivism, in which students become active learners and take more responsibility for their own learning. Students have to learn to construct knowledge on their own and determine their own learning styles (Duffy \& Jonassen, 1992). They also play active roles in knowledge sharing and are encouraged to show visibility and take ownership in their community of learning (Kim, 2013). Collaborative learning means that students work in groups of two or more, mutually searching for understanding, solutions, and meanings, or creating products. Meanwhile, collaborative learning also involves engaging individuals as members of a group to facilitate learning, which also involves the phenomena seen in negotiated sharing of meanings, and further to construct group cognition.

Much research has focused on developing better technologies and environments in support of collaborative learning. Some notable examples (i.e., Dewiyanti et al., 2007; Stahl, 2005; Stahl et al., 2006; Suchman, 1995) are computer-based learning (CBL), computer-supported collaborative learning (CSCL), computer-supported collaborative work (CSCW), and computer-mediated communication (CMC). These concepts and their applications (e.g., in forums, e-mail, electronic voting systems, and synchronous teleconferencing systems), have facilitated interactions among learners and helped them to achieve quality through group learning. Since the development of Web 2.0 technology, many applications have been widely adopted by teachers and applied to facilitate collaborative writing in the classroom, with an emphasis on how a computer-based writing environment can meet users' needs and support specific writing tasks (Chu \& Kennedy, 2011; Kear, Woodthorpe, Robertson \& Hutchison, 2010; Meyer, 2010).

Web 2.0, as proposed by O’Reilly (2000), was thought to be a powerful network that would become a platform and spread into all connective devices. Emphasising the consumption and remixing of data from multiple sources, it aims to create network effects through an architecture of participation, where users of Web 2.0 applications are seen as both readers and co-authors. Individuals contribute their own data, share their thoughts, and provide services in a form that allows modifications. Adopting the concept of Web 2.0 in learning, Wever, Keer, Schellens and Valcke (2011) proposed three main perspectives that emphasise learning interaction in this environment. First, Web 2.0 is a two-way channel, in effect a reading and writing Web where students are empowered. Second, it is an architecture of participation that enables students to create their self-regulated, collaborative work on the Web. Last, it is the combination of 
programming frameworks and language to create a rich user experience in order to deliver applications entirely through a Web browser.

Noël and Robert (2003) proposed that a computer-supported collaborative writing application should have the following features: First, the application should provide a shared virtual working space that enables students to share their artefacts. Second, it should include communication tools in order to facilitate interactions between writers and co-writers and to promote awareness among the group members. Third, it should help writers to coordinate their actions and support different writing strategies. Members then can play multiple roles on the system. Fourth, it must support students either in conducting a long-term plan or in participating in several projects at the same time. Last, students' contributions must be protected. Web 2.0 applications make such features possible.

As the Wiki emerged as a platform for collaborative authoring, it also qualifies as a computer-supported collaborative writing tool, as confirmed by Parker and Chao (2007). Elgort, Smith and Toland (2008) also reported that both students and instructors saw value in using Wikis as a collaborative tool, especially in light of the better individual participation and information organisation for group projects. Forte and Bruckman (2006) further investigated links between students' Wiki publishing experiences and writing to learn in an undergraduate government course, and found that students could perceive the audience of their work, which in turn helped them to monitor the quality of their writing. Other studies (i.e., Bower, Woo, Roberts \& Watters, 2006; Choy \& Ng, 2007) reported failures on adopting Wikis in different courses caused by underestimation of the importance and nature of task authenticity and pedagogical design in collaborative learning. However, previous researchers have tended to focus on how students work with the content, without providing evidence of what motivates them to use and interact in this kind of learning environment. Guo and Stevens (2011) tried to explore the factors influencing college freshmen's perceptions of Wikis in group learning and revealed that students' prior Wiki experience influenced their perceptions of the usefulness of Wikis. However, empirical research addressing these complex factors, especially in a model view, is still rather limited. The current study aims to contribute to the research base of Wiki applications in higher education.

\section{Acceptance and use of technology: The UTAUT Model}

The Unified Theory of Acceptance and Use of Technology (UTAUT), proposed by Venkatesh et al. (2003), extended the original Technology Acceptance Model (TAM) by Davis (1989) by explaining the differences in how people accept and use technology in the workplace. The original TAM aimed to explain the acceptance of information technology in terms of how users perceive the usefulness and ease of technology, which in turn would affect their internal beliefs, attitudes toward the technology, and intention of adoption. The TAM model has become widely used over the past few decades, along with the development of information technology.

Based on studies of the adoption of eight competing models in information systems, Venkatesh et al. (2003) developed the UTAUT Model, and proposed more factors that would influence the acceptance and use of technology and categorised them as direct and indirect determinants. They further contended that performance expectancy, effort expectancy, and social influence were direct determinants that predicted intentions to use technology, and facilitated the direct determinants conditions of usage behaviour. Some researchers have tried to apply TAM and its extended models in educational contexts, such as in the adaptations of e-learning systems or Web-based learning environments (Lee, 2010; Liao, To, Liu, Kuo \& Chuang, 2011; Maldonado, Khan, Moon \& Rho, 2009).

\section{The Extended UTAUT Model for collaborative learning with a Wiki system}

Previous studies did not measure actual behavior in the UTAUT model. However, whether or not users actually use the system and how they perform with the new technology are of special importance in understanding the intervention from an ethnographic perspective (Suchman, 1995). Therefore, the current study attempts to modify the original UTAUT model, and also to extend the exploration of factors affecting student adoption of a Wiki system for their online collaborative learning and their intentions to continue using the system. To extend this model, this study considers the facilitating conditions as determinants of actual usage of the Wiki system, and the actual usage behaviour, performance expectancy, 
effort expectancy, and social influence, as determinants of behavioural intention to continue using the Wiki system in the future. Figure 1 represents the construction and relations of the Extended UTAUT model proposed by researchers of this study in using a Wiki system in collaborative educational writing tasks.

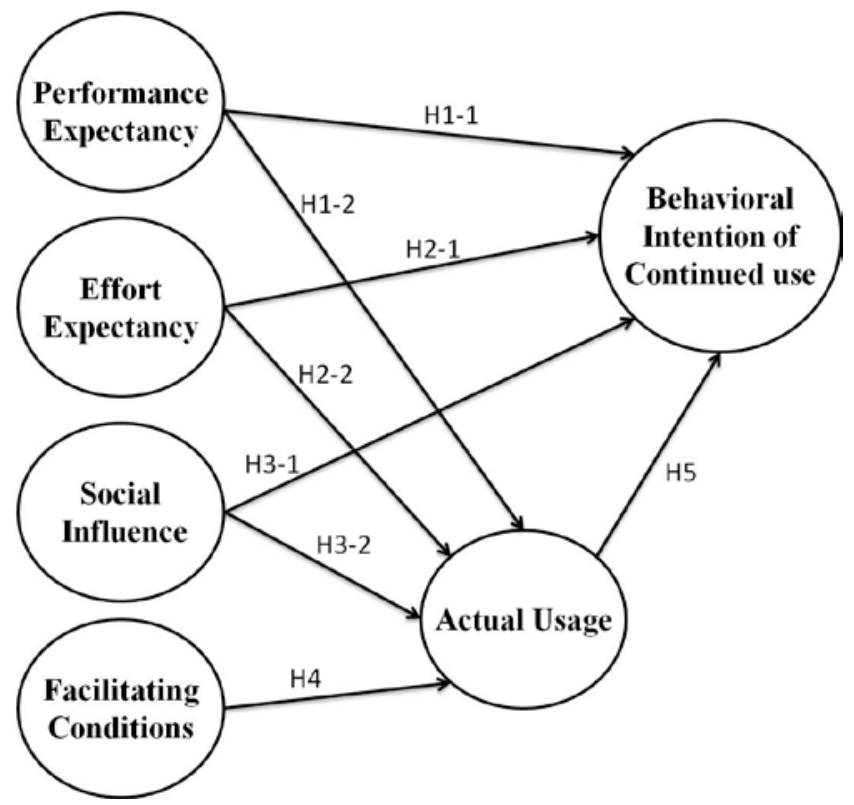

Figure 1. Extended UTAUT Model for collaborative learning with a Wiki system

\section{Performance expectancy}

Performance expectancy is defined as the degree to which individuals believe that using the system will help them to attain gains in job performance (Venkatesh et al., 2003). While collaboration has traditionally been considered as a means to improve group performance, relevant studies have also examined the relationships between students' expectancy and their performance in collaboration. Mercier, Booker and Goldman (2003) investigated what students value the most in collaborative endeavours and found that open communication among group members is essential for effective collaboration. Tsinakos (2006) proposed that the expected outcomes - user feedback, impact on learning, impact on grades, non-obtrusive measures of usage patterns, and external measures of quality of the content generated - may contribute to the improvement of students' collaborative work on Wikis. Maldonado, Lee, Klemmer and Pea (2007) reported that student usage of collaborative tools increased when they believed that it would enable their group to accomplish tasks together. According to UTAUT, performance expectancy is constructed if students perceive a Wiki as useful in completing their group term report. It will spur the construction of their performance expectancy, which in turn enables them to accomplish the group term report more quickly. Ong and Lai (2004) also provided empirical support for the relationship between perceived usefulness of an adapted e-learning system in an organisation and behavioural intentions of using it. According to the expectancy model proposed by Robey (1979), a user perception assessment through performance of use is a direct determinant of system use. Therefore, this study proposes the following hypotheses.

H1-1: Performance expectancy positively affects students' intentions of continued use of Wiki systems for individual and collaborative learning in the future.

H1-2: Performance expectancy positively affected students’ actual use of Wiki systems for individual and collaborative learning in this semester. 


\section{Effort expectancy}

Effort expectancy is defined as the perceived degree of ease associated with the use of information systems (Venkatesh et al., 2003). Davis (1993) assumed that a system that is perceived as simple or easy to use would be more likely to induce users' perceptions of usefulness and behavioural intentions to use it. This is the extended concept of perceived ease of use in the original technology acceptance model. Regarding the use of Wikis in teamwork, Wei et al. (2005) found that the interface of a Wiki actually mediated the distributed members' experience of working with each other. Wikis have enabled students to create links to old pages, implement version control (Erkens, Jaspers, Prangsma \& Kanselaar, 2005), and use preliminary security control to process their collaborative task well. Therefore, students will develop effort-expectancy based on their interaction with a Wiki: how easily students become skilful in using the technology, and how easily they can learn to operate it. In addition, Sadd and Bahli (2005) indicated that ease of use was positively associated with perceived usefulness and behavioural intentions. Accordingly, this study proposes the following hypotheses.

H2-1: Effort expectancy positively affects students' intention of continued use of a Wiki system for individual and collaborative learning in the future.

H2-2: Effort expectancy positively affected students’ actual use of the Wiki system for individual and collaborative learning in this semester.

\section{Social influence}

Social influence is defined as the degree to which an individual perceives as important the fact that others believe that he or she should use the new system (Venkatesh et al., 2003). A Wiki provides group members with a shared online space to store documents, exchange information, and work collaboratively, and provides the public with searchable information, wherein the provision of information by a specific user to larger audiences may attract contributors who are willing to add or edit its contents. Many technical communicators have been using Wikis for co-authoring works, such as collaborative programming projects proposed by their teammates. When Wikis are applied in learning, Chao and Huang (2007) reported, students who go on Wiki pages and start editing enhance their awareness of writing. In addition, Wei et al. (2005) proposed that students would update pages as desired to make their Web presence feel alive and dynamically satisfy audiences. Some studies have also shown how social influences contribute to one significant indicator to predict behavioural intentions of technology acceptance (Kim \& Malhotra, 2005b; Yeh, Lin \& Lu, 2011). In a class, as in this study, students may perceive the construction of social influence based on the degree to which they believe their teaching assistants, teammates, and classmates (those in other groups) think that they should use a Wiki. Schmitz and Fulk (1991) proposed a social influence model of technology use, postulating that individuals' perceptions and use are socially constructed. Therefore, this study proposes the following hypotheses.

H3-1: Social influence positively affects students' intention of continued use of a Wiki system for individual and collaborative learning in the future.

H3-2: Social influence positively affected students’ actual use of Wiki system for individual and collaborative learning in this semester.

\section{Facilitating conditions}

Facilitating conditions are defined as the degree to which an individual believes that an organisational and technical infrastructure exists to support the use of the information system (Venkatesh et al., 2003). Facilitating conditions may include technological and environmental aspects that are designed to remove barriers impeding the use of systems. Daugherty and Funke (1998) conducted a study in which 76 faculty members responded to barriers that they confronted when incorporating distance education. The main barrier was a lack of faculty/administration support. In an educational context, students' perceived facilitating conditions will be influenced by the degree to which they believe their teaching assistant, teachers, and their classmates are available for assistance when they encounter difficulties in using a technology. As for using a Wiki for learning or collaboration, although a Wiki provides a flexible page for users, they still have to learn the Wiki syntax to edit a Wiki page. It may be easy for an experienced programmer, but not for a novice. Davies (2004) suggested that initial training may be particularly important when trying to engage users in Wiki-based collaboration. In addition to technological problems, 
some other conditions are also important to facilitate the adoption of a Wiki system, such as setting up clear goals and policies for system use, providing rewards, and nurturing a collaborative working environment to empower users. Based on the aspects discussed here, this study proposes the following hypothesis.

H4: Facilitating conditions positively affected students' actual usage of a Wiki system for individual and collaborative learning in this semester.

\section{Actual usage and behavioural intention of future usage}

Actual usage is defined as a user's intention to take a specific action (Bagozzi, 1981). Behavioural intention is defined as the degree to which an individual will adopt the application in the future (Venkatesh, 2000), which can be seen as a predictor of future use of an information system or technology. Under the educational context in this class, students actually used the system as required by the instructor, and may or may not continue using it in future learning. Therefore, students' actual usage of the Wiki was measured by their self-reported average time spent on the Wiki system per week, whereas students' behavioural intention of future usage was constructed from their intention to use individual Wiki pages, or plans to use a Wiki system to help with their group term report and collaborative learning, as well as to extend their learning to other courses in the next semester or in the future.

Previous studies reported that after controlling for past behaviour, the influence of behavioural intention on actual behaviour in the future dropped considerably (Bagozzi, 1981). Kim and Malhotra (2005a) found that past behaviour affects users' behavioural intention; their findings also supported that users' behavioural intention and their past usage behaviour could be the predictors of future use. While previous studies tended to evaluate the technology acceptance with a future behaviour prediction approach, this study tries to measure the actual use behaviour and then use the results, along with other indicators, to predict behaviour intentions of continued use of the system in the future. Therefore this study defines actual usage as students' self-reported usage of the Wiki system, and the behavioural intention of future usage as users' intention to continue to use the Wiki system in the future. The hypothesis is set as follows:

H5: Students' actual usage of the Wiki system this semester positively affected students' intention to continue using the Wiki system for individual and collaborative learning in the future.

\section{Methodology}

\section{Context}

This study was implemented in a semester-long course offered in a research university in Taiwan. The course was designed for undergraduate students to learn various issues in gender relations. During each class meeting, one or two gender-related topics were presented by guest-speakers with different specialties. After the lecture, students were asked to join learning groups led by teaching assistants to reflect on and share their gender experiences, as related to the lecture topic. Students were also assigned group projects that required them to work in teams throughout the semester. In addition, a Wiki system was established, wherein individual group Wiki pages were provided to the students. On these pages, they were expected to discuss their projects and collaboratively develop their learning and group work. After the Wiki system was used for one semester, a survey was conducted to investigate students' experiences and to analyse their collaborative writing performance on the Wiki system. Besides, while the researchers were also instructors to the class, students use behaviours were observed periodically and recorded for further analysis.

\section{Survey instrument}

Drawing on previous theoretical discussions of what possible affective factors may influence students' acceptance and use of the Wiki system in their collaborative learning tasks, an Extended UTAUT collaborative writing questionnaire was developed to measure students' performance expectancy, effort expectancy, social influences, facilitating conditions, behavioural intention of future use, and actual usage of the Wiki system. The questionnaire consisted of two parts. The Wiki-UTAUT part contained 12 items 
(see Appendix A.) with a 6-point Likert-like scale, with "1" representing strongly disagree and "6" representing strongly agree. These items were modified from early studies to ensure their relevance to the online collaborative writing context in this study (Venkatesh et al., 2003). This survey questionnaire was reviewed by three experts of learning technology and gender education for confirmation of adequate expert validity. Also, the internal consistency of this instrument attained a rather reliable level in pretest (Cronbach's $\alpha=0.91$ ). The second part contained items to collect student background information and Wiki experience, such as students' demographic data (three items, gender, years in college, and major), Wiki system experience (three items, system used, function used, and purpose for use), and their own self-reported usage of the CourseWiki system (one open question).

\section{Wiki system}

The researchers of this study set up the Wiki system with the MediaWiki software, an open-source program used not only for Wikimedia projects but also for many other websites. Specifically, the software was MediaWiki version 1.9 with PHP scripts and a MySQL database. The system provided administrative functions such as setting permissions, customising extensions, changing the site appearance, and better editing functions, including tracking edited data, file uploading, and data storage in a database.

\section{Data collection and analysis}

The questionnaires were administered to all students during the final class meeting of the course. Statistical Package for the Social Sciences (SPSS 14.0) was used for descriptive analysis, and the hypothesised relationships were tested using the Structure Equation Modeling of LISREL 8.72.

\section{Results}

\section{Subjects}

The sample size usually plays an influential role in the reliability test during structural equation model (SEM) analysis. Bollen (1989) recommended a minimum sample size of at least 100. The subjects in this study were 103 undergraduate students in a gender-related general education course, with valid returns of an equal 103 questionnaires. Of the 103 subjects who participated in this research, 60 were male (58.3\%) and 43 were female (41.7\%). The respondents were sophomores (62 students, $60.2 \%$ ), seniors (20 students, 19.4\%), juniors (14 students, 13.6\%), and freshmen (7 students, 6.8\%). All students were from different departments in the university, with great diversity in majors. Table 1 summarises the details of our subjects. 
Table 1

Profile of the subjects

\begin{tabular}{lcc}
\hline Variable & Frequency & Percentage (\%) \\
\hline Gender & & \\
Male & 60 & $58.3 \%$ \\
$\quad$ Female & 43 & $41.7 \%$ \\
Year & & \\
Freshman & 7 & $6.8 \%$ \\
Sophomore & 62 & $60.2 \%$ \\
Junior & 14 & $13.6 \%$ \\
Senior & 20 & $19.4 \%$ \\
Major & & \\
Bio-Resources and Agriculture & 18 & $17.5 \%$ \\
Liberal Arts & 15 & $14.6 \%$ \\
Science & 16 & $15.5 \%$ \\
Engineering & 15 & $14.6 \%$ \\
Electrical Engineering and Computer Science & 11 & $10.7 \%$ \\
Management & 9 & $8.7 \%$ \\
Social Science & 9 & $8.7 \%$ \\
Life Science & 4 & $3.9 \%$ \\
Public Health & 2 & $1.9 \%$ \\
Veterinary medicine & 4 & $3.9 \%$ \\
\hline Total & 103 & $100 \%$ \\
\hline
\end{tabular}

\section{Reliability and validity of measurement}

The internal reliability and the composite reliability of the Wiki- UTAUT part of the questionnaire were analysed. Results indicated that the Cronbach's alpha coefficient of the instrument was 0.943, signifying good internal consistency. All the composite reliability values exceeded 0.5 , representing a commonly acceptable level for confirmatory research procedures. This study also met applicable validity measures suggested by Fornell and Larcker (1981); the average variance extracted for each construct should exceed 0.5 due to measurement error for that construct. All the convergent validity values exceeded 0.5 , confirming that the validity measures of the convergent instrument were proper. In short, the instrument used in this study exhibited good levels of both reliability and validity (see Table 2).

Table 2

Reliability and validity analysis of the instrument (Wiki-UTAUT)

\begin{tabular}{lcc}
\hline \multicolumn{1}{c}{ Variables } & Composite & Convergent \\
& Reliability & Validity \\
\hline Performance Expectancy (PE) & 0.8247 & 0.9033 \\
Effort Expectancy (EE) & 0.8698 & 0.9300 \\
Social Influence (SI) & 0.6481 & 0.7864 \\
Facilitating Conditions (FC) & 0.5481 & 0.655 \\
Behavioural Intention of Future Use (BIFU) & 0.8725 & 0.9535 \\
\hline
\end{tabular}

\section{Descriptive statistics analysis}

The descriptive statistics of measurement items are shown in Table 3. Participants reported that during the semester, they usually spent 30 minutes to one hour per week on the CourseWiki system. Except for items FC2, IU1, IU2, and IU3, all means were 3 or higher, indicating a positive response to the constructs measured in this study. The standard deviations ranged from 0.90 to 1.28, indicating a narrow spread of item scores around the mean. Based on the open-question comments the students provided, the reason they did not intend to use the Wiki in the future was that they did not expect other teachers to use the Wiki system in the courses they would take in following semesters. 
Table 3

Results of estimate parameter indicators for latent variables

\begin{tabular}{|c|c|c|c|c|c|}
\hline $\begin{array}{l}\text { Latent } \\
\text { variable }\end{array}$ & Indicators & Mean & S.D. & Loading & t-value \\
\hline Performance & PE1 & 3.515 & 1.282 & 0.83 & -- \\
\hline Expectancy & PE2 & 3.359 & 1.212 & 0.98 & $10.32^{* * *}$ \\
\hline Effort & EE1 & 3.301 & 1.259 & 1.00 & $\begin{array}{ll}- \\
\end{array}$ \\
\hline Expectancy & EE2 & 3.689 & 1.188 & 0.86 & $9.25^{* * *}$ \\
\hline Social & SI1 & 3.388 & 1.254 & 0.81 & -- \\
\hline Influence & SI2 & 2.835 & 1.189 & 0.80 & $6.75^{* * *}$ \\
\hline Facilitating & FC1 & 3.689 & 1.057 & 1.16 & -- \\
\hline Condition & FC2 & 3.495 & 0.989 & 0.31 & 1.77 \\
\hline Behavioural & BIFU1 & 2.583 & 1.217 & 0.88 & - \\
\hline Intention of & BIFU2 & 2.670 & 1.200 & 0.96 & $14.73^{* * *}$ \\
\hline Future Use & BIFU3 & 2.709 & 1.250 & 0.96 & $15.35^{* * *}$ \\
\hline Actual Usage & $\mathrm{AU}$ & 1.990 & 1.000 & 1.00 & -- \\
\hline
\end{tabular}

\section{Model estimation and hypothesis testing}

This study applied structural equation modeling to test the adequacy of the measurement model. Table 3 presents the results of analysis of the estimated parameter indicators for latent variables. Results indicate that most of the indicators reflected each concept of its factor $(p<0.001)$. Further analysis of the study showed paths on the coefficients amongst each factor. As shown in Table 4, hypotheses 2-2, 3-1, and 5 were confirmed, and hypotheses 1-1, 1-2, 2-1,3-2, and 4 were not supported. Parameter estimation revealed that students' effort expectancy had direct effects on students' actual usage of the Wiki system during their individual and collaborative learning (H2-2: $\gamma=0.05, p<0.05)$. It also confirmed that both the students' perceived social influence and their actual usage of the Wiki system had significant impacts on behavioural intention of future use (H3-1: $\gamma=0.39, p<0.05$; H5: $\beta=0.33, p<0.01$ ). Students' performance expectancy and effort expectancy had non-significant effects on behavioural intention of future use (H1-1: $\gamma=0.07, p>0.05$; H2-1: $\gamma=0.29, p>0.05$ ). Both students' performance expectancy and their perceived social influence had direct effects on their actual usage of the Wiki system for individual and collaborative learning, but the effects were insignificant (H1-2: $\gamma=0.09, p>0.05$; H3-2: $\gamma=0.15, p>0.05$ ).

Table 4

Results of estimated parameters of path coefficients

\begin{tabular}{lcl}
\hline Hypothesis & $\begin{array}{c}\text { Standardised } \\
\text { coefficients }\end{array}$ & t-value \\
\hline H1-1: PE-> BIFU & 0.07 & 0.60 \\
H1-2: PE-> Usage & 0.09 & 0.69 \\
H2-1: EE-> BIFU & 0.29 & 0.50 \\
H2-2: EE-> Usage & 0.05 & $2.78^{*}$ \\
H3-1: SI-> BIFU & 0.39 & $2.95^{*}$ \\
H3-2: SI-> Usage & 0.15 & 1.10 \\
H4:FC->Usage & 0.09 & 0.90 \\
H5:Usage->BIFU & 0.33 & $3.59^{* *}$ \\
\hline
\end{tabular}

Note: ${ }^{*} p<0.05 ; * * p<0.01$

To determine a good model fit, Bentler (1990) suggested that the Chi-square value, normalised by degrees of freedom $(x / d f$.), should not exceed 3, the goodness of fit index (GFI) should exceed 0.9, the non-normed fix index (NNFI) and comparative fit index (CFI) should exceed 0.9, and the root mean square error of approximation (RMSEA) should not exceed 0.08. The NNFI and CFI values are not sensitive to sample size, so values near 0.90 indicate a good model fit (Browne \& Cudeck, 1992). Results of the model estimation in this study were all within satisfactory ranges $(x / d f .=1.54, x=64 ; d f=44$, GFI = 
$0.90, \mathrm{NFI}=0.95, \mathrm{NNFI}=0.97, \mathrm{CFI}=0.98$, and RMSEA $=0.07$ ), suggesting an adequate model fit (see Table 5).

Table 5

Results of model estimation of the research models

\begin{tabular}{lccc}
\hline Goodness-of-fit measure & Recommended value & Entire sample & Accepted \\
\hline$\chi^{2}$ degree of freedom & $\leqq 3.00$ & 1.54 & $\checkmark$ \\
Goodness-of-fit index (GFI) & $\geqq 0.90$ & 0.90 & $\checkmark$ \\
Normed-fit index (NFI) & $\geqq 0.90$ & 0.95 & $\checkmark$ \\
Non-normed fit index (NNFI) & $\geqq 0.90$ & 0.97 & $\checkmark$ \\
Comparative fit index (CFI) & $\geqq 0.90$ & 0.98 & $\checkmark$ \\
Root mean square error of & $\leqq 0.08$ & 0.075 & $\checkmark$ \\
approximation(RMSEA) & & & \\
\hline
\end{tabular}

\section{Discussion and conclusions}

\section{Factors affecting the intention of using Wiki for collaborative learning for the future}

This study found that the use of Wiki technology has a significant potential to support and enhance in-class individual and collaborative learning in a university-level course on gender. Unlike previous studies (i.e., Guo \& Stevens, 2011), which tried to identify factors influencing students' Wiki using experiences with one item question for every dimension and in a more freely exploratory way, this study tried to investigate key factors that influence students' continued use of Wikis for online collaborative tasks through an Extended UTAUT model proposed by the researchers. The results validated the good fit of the Extended UTAUT model and confirmed actual use as an important factor that may moderate expected efforts for continuing use in the future. Results of this study show that the effort expectancy perceived by the students will initially affect their actual usage of a Wiki for online individual and collaborative learning during a semester. Results also show that the higher students' perceived ease of use of a Wiki, the more often they will use a Wiki for individual and collaborative learning. That students also perceived social influence while actually using the Wiki provides a potential way to predict students' perceived behavioural intention of using a Wiki to support and enhance online individual and collaborative learning in the future, which confirms research hypotheses 2-2, 3-1, and 5 (see Table 6). In addition, if students perceive the importance of their own usage of the Wiki system to others, such as teammates and teaching assistants, it will motivate them to continue using the system in the future. Furthermore, students' actual usage of the Wiki during the learning process increases their behavioural intention to use the Wiki system for individual and collaborative learning. 
Table 6

Summary of hypotheses testing results

\begin{tabular}{|c|c|}
\hline Hypothesis & Result \\
\hline $\begin{array}{l}\text { H1-1: Performance expectancy positively affects students' intentions } \\
\text { of continued use of Wiki systems for individual and collaborative } \\
\text { learning in the future. (PE-> BIFU) }\end{array}$ & Not supported \\
\hline $\begin{array}{l}\text { H1-2: Performance expectancy positively affected students' actual use } \\
\text { of Wiki systems for individual and collaborative learning in this } \\
\text { semester. (PE-> Usage) }\end{array}$ & Not supported \\
\hline $\begin{array}{l}\text { H2-1: Effort expectancy positively affects students' intention of } \\
\text { continued use of a Wiki system for individual and collaborative } \\
\text { learning in the future. (EE-> BIFU) }\end{array}$ & Not supported \\
\hline $\begin{array}{l}\text { H2-2: Effort expectancy positively affected students' actual use of the } \\
\text { Wiki system for individual and collaborative learning in this semester. } \\
\text { (EE-> Usage) }\end{array}$ & Supported \\
\hline $\begin{array}{l}\text { H3-1: Social influence positively affects students' intention of } \\
\text { continued use of a Wiki system for individual and collaborative } \\
\text { learning in the future. (SI-> BIFU) }\end{array}$ & Supported \\
\hline $\begin{array}{l}\text { H3-2: Social influence positively affected students' actual use of Wiki } \\
\text { system for individual and collaborative learning in this semester. (SI-> } \\
\text { Usage) }\end{array}$ & Not supported \\
\hline $\begin{array}{l}\text { H4: Facilitating conditions positively affected students' actual usage } \\
\text { of a Wiki system for individual and collaborative learning in this } \\
\text { semester. (FC-> Usage) }\end{array}$ & Not supported \\
\hline $\begin{array}{l}\text { H5: Students' actual usage of the Wiki system this semester positively } \\
\text { affected students' intention to continue using the Wiki system for } \\
\text { individual and collaborative learning in the future. (Usage->BIFU) }\end{array}$ & Supported \\
\hline
\end{tabular}

However, in this study, students' expectancy of performance in using the Wiki system directly affected actual use, and their behavioural intention continued, although the results were insignificant. According to the past literature, expectancy of performance, which is task-oriented, can help users achieve task-related objectives, such as task efficiency and effectiveness (Gefen \& Straub, 2000). For the efficiency, students felt Wiki was useful in their group term report, and for effectiveness, Wiki provided a platform for discussion that enabled them to accomplish their group term report more quickly. According to Mercier et al. (2003), students value collaborative endeavours the most, and open communication amongst group members was found to be essential for effective collaboration. In the context of this study, the Wiki served not only as a platform for students' learning groups to finish their collaborative task, but also as a medium of communication among the students. According to Karahanna and Straub (1998), social presence is a key factor for users to perceive a computer-based communication medium as useful. Social presence is the degree to which a medium conveys the psychological presence of the sent message. Face-to-face communication, for example, would be characterised as having high social presence, while electronic and text-based media would be characterised as having low social presence. A Wiki that is text-based, without graphics or exciting colors, would fit into the low social presence category. Within the context of a general education course in a university, students have to work with team members from different colleges; therefore, communication issues will affect the ability of the diverse team members to finish a collaborative task. In the Wiki system, if students need to communicate with each other, it is easy for them to paste their words onto the pages. The only disadvantage is that they may have to wait for others to post responses. This inconvenience of communication may have affected students' perceptions of and performance on the Wiki platform. 
Furthermore, students also perceived that the social influence of others was an important factor while directly using the Wiki system, but the effect was insignificant. The text-based design of the Wiki system stated above supports what Garramone, Harris and Anderson (1986) proposed, namely that the lower the level of social presence, the lower the interaction created. Individual relations, dynamic relations, and group relations are three operatives of social influence. Students' evaluations of their communicative networks, similar adoption behaviours (Rice, Grant, Schmitz \& Torobin, 1990), and group memberships (Festinger, 1954) will affect their attitude and behaviours toward new technology. However, the low interaction between learning groups may reduce group membership among group members, in turn reducing the effect of students' perceived social influence of others while actually using the Wiki system for individual and collaborative learning.

Facilitating conditions had insignificant effects during the actual usage of the Wiki system. Although Wikis have been described as easy to use, Elgort et al. (2008) argued that not every student is a competent or skilled ICT user. Students from this study were introduced to the Wiki system in a short training session at the beginning of the semester, and as suggested by Wei et al. (2005), while the design of a Wiki remains very primitive if it is not customised, it appears that the Wiki system is still not easy enough for them to use effectively, especially when they are new to the collaborative environment. For example, in the Wiki system, if students want to publish their work, it is easy for them to type in the word processor, but it is troublesome for users to type the " $<$ br $>$ " syntax to skip lines. Furthermore, if students want to customise their group Wiki pages, they have to learn to use advanced Wiki syntax, which is inconvenient. In addition, even though students still lack proficiency in using a Wiki, they still have to go on group pages to complete their collaborative tasks, adding further complications.

\section{Observations and feedbacks of students' collaborative learning in using the Wiki system}

When observing students' collaborative writing performance on the Wiki system, it was found that student groups shared their ideas by effectively posting their thoughts on their group Wiki pages. In total, the Wiki pages were visited 133,212 times and edited 3,671 times in one semester. Moreover, as students reported to the open question in the survey, they also reflected on their learning with group projects using Wiki pages. When students went on their group pages to work on their projects, the Wiki pages flourished as group members engaged in the process. This kind of learning approach may reflect some important characteristics of Web 2.0. As part of developing understanding of the affective factors that influence students' collaborative learning behaviour, the results support that Wiki could enable extreme, rich, and flexible collaborations amongst students. The students in this study demonstrated that the Wiki helped them to accomplish collaborative tasks; however, they also reported some inconvenience in frequency of communication, advanced editing, and management of their Wiki pages.

\section{Implications in adopting Wikis for teaching and learning practice}

Advocators of Web 2.0 tools usually promote ideas and applications of lightweight user interfaces, such as using a general browser, and help users contribute their knowledge in hopes of further harnessing collective intelligence. O’Reilly (2000) proposed the Wiki as a typical word processor to represent Web 2.0 tools supporting collaborative editing and rich formatting. It represents the new interactive style between users and the Internet. To this end, applying a Wiki in an educational context is expected to support collaborative learning among student peers, and even go beyond blogs in bringing a logic of abduction into the educational process (Kang \& Glassman, 2011). Similar to what Duffy and Axel (2006) found in their research, this study also confirms that using the Wiki system did enable group members to share their ideas and reflections regarding their projects, to add summaries of their thoughts from the prescribed readings, to document their works, and to develop ongoing research projects in their learning groups. However, more technical mechanisms, such as RSS, instant messaging systems, or visualisation of learning activities could be embedded into Wiki systems to facilitate frequent group communication and deepen interaction amongst learning groups in the collaborative learning context (Yueh \& Hsu, 2008; Yueh, Lin, Liu, Shoji, \& Minoh, 2014). Moreover, this study supports Frydenberg (2008), who argued as well that teachers could use Wikis for distributing course information, building online learning contents, and leading collaborative writings. Parker and Chao (2007) have also suggested that Wikis enable users in educational communities to monitor the constantly changing states of ideas and discuss emerging issues. This study therefore recommends the further advancement of applications of Wikis in educational contexts to support teachers in managing classroom activities effectively. For example, teachers can 
utilise the version control and history tracking functions of Wiki to monitor students' collaborative learning. Yet it is important to note that it is very important to remove the barriers to using Wikis in the early implementation of a Wiki system.

\section{Implications for research}

As this study was conducted in a specific course, any generalisation of its result to other contexts should be done with caution. In addition, although the sample size was still valid for the analysis, the size of the class was limited. The small sample size may have been reason some results were non-significant. Further studies from more courses with larger subjects are recommended in order to provide sufficient evidence. Furthermore, future research should focus on how Wikis can best support teaching and learning, how instructors can facilitate the adoption and effective use in an interactive learning environment, and how instructors can sustain students' motivation and encourage them to continue using Wikis to support their learning. Future research can also examine qualitative accomplishments with quantitative research methods to understand how students perceive social influences in their communication, interaction, and membership, all of which would affect their actual usage of Wiki systems and support their individual and collaborative learning behaviours. In addition, the social presence on the Wiki platform affects students' intentions of continued use, and the actual usage behaviour in the collaborative learning context may be another interesting issue for researchers to explore in the future.

\section{Acknowledgements}

The authors would like to thank Taiwan National Science Council (NSC100-2628-S-002-001-MY3) for their grants that partially support this study.

\section{Reference List}

Bagozzi, R. P. (1981). Attitudes, intentions and behavior: A test of some key hypothesis. Journal of Personality and Social Psychology, 40(4), 607-627. doi:10.1037/0022-3514.41.4.607

Bentler, P. M. (1990). Comparative fit indexes in structural models. Psychological Bulletin, 107(2), 238246. doi:10.1037/0033-2909.107.2.238

Bollen, K. A. (1989) Structural equations with latent variables. New York, NY: John Wiley \& Sons. doi:10.1002/9781118619179

Boulos, M., Maramba, I., \& Wheeler, S. (2006). Wikis, blogs and podcasts: A new generation of Web-based tools for virtual collaborative clinical practice and education. BMC Medical Education, 6(41), 1-8.

Bower, M., Woo, K., Roberts, M., \& Watters, P. (2006). Wiki pedagogy - A tale of two wikis. Proceedings of the 7th International Conference on Information Technology Based Higher Education and Training, 191-202. doi:10.1109/ithet.2006.339764

Browne, M. W., \& Cudeck, R. (1992). Alternative ways of assessing model fit. Sociological Methods \& Research, 21(2), 238-250. doi:10.1177/0049124192021002005

Chao, Y. C., \& Huang, C. K. (2007). The effectiveness of computer-mediated communication on enhancing writing process and writing outcomes: Implementation of blog and Wiki in the EFL writing class in Taiwan. Proceedings of World Conference on Educational Multimedia, Hypermedia \& Telecommunications, Norfolk, VA: AACE, 3463-3468.

Chiu, C. M., \& Wang, E. T. G. (2008). Understanding Web-based learning continuance intention: The role of subjective task value. Information \& Management, 45(3), 194-201. doi:10.1016/j.im.2008.02.003

Choy, S. O., \& Ng, K. C. (2007). Implementing wiki software for supplementing online learning. Australasian Journal of Educational Technology, 23(2), 209-226.

Chu, K. W. S., \& Kennedy, D. M. (2011). Using online collaborative tools for groups to co-construct knowledge. Online Information Review, 35(4), 581-597. doi:10.1108/14684521111161945

Daugherty, M., \& Funke, B. L. (1998). University faculty and student perceptions of web-based instruction. Journal of Distance Education, 13(1), 21-39.

Davies, J. (2004). Wiki brainstorming and problems with Wiki-based collaboration. York, UK: University of York. 
Davis, F. D. (1989). Perceived usefulness, perceived ease of use, and user acceptance of information technology. MIS Quarterly, 13(3), 318-340.

Davis, F. D. (1993). User acceptance of information technology: System characteristics, user perceptions and behavioral impacts. International Journal of Man-Machine Studies, 38(3), 475-487. doi:10.2307/249008

Dewiyanti, S., Brand-Gruwel, S., Jochems, W., \& Broers, N. J. (2007). Students’ experiences with collaborative learning in asynchronous computer-supported collaborative learning environments, Computers in Human Behavior, 23(1), 496-514. doi:10.1016/j.chb.2004.10.021

Duffy, P., \& Axel, B. (2006). The use of blogs, Wikis and RSS in education: A conversation of possibilities. Proceedings of Online Learning and Teaching Conference 2006 Brisbane, Australia, 3638.

Duffy, T. M., \& Jonassen, D. H. (1992). Constructivism and the Technology of Instruction: A Conversation. Hillsdale, NJ: Lawrence Erlbaum Associates.

Eales, R. T. J., Hall, T., \& Bannon, L. J. (2002). The motivation is the message: Comparing CSCL in different settings. Proceedings of the Conference on Computer Support for Collaborative Learning: Foundations for a CSCL Community (pp. 310-317). doi:10.3115/1658616.1658660

Elgort, I., Smith, A. G., \& Toland, J. (2008). Is wiki an effective platform for group course work? Australasian Journal of Educational Technology, 24(2), 195-210.

Engstrom, M. E., \& Jewett, D. (2007). Collaborative learning the wiki way. TechTrends, 49(6), 12-15. doi:10.1007/BF02763725

Erkens, G., Jaspers, J., Prangsma, M., \& Kanselaar, G. (2005). Coordination processes in computer-supported collaborative writing. Computers in Human Behavior, 21(3), 463-486.

Festinger, L. (1954). A theory of social comparison processes. Human Relations, 7, 117-140. doi:10.1177/001872675400700202

Fornell, C., \& Larcker, D. F. (1981). Evaluating structural equation models with unobservable variables and measurement error. Journal of Marketing Research, 18(1), 39-50.

Forte, A., \& Bruckman, A. (2006). From Wikipedia to the classroom: Exploring online publication and learning. Proceedings of International Conference on Learning Sciences, Bloomington, Indiana, 182 188.

Frydenberg, M. (2008). Wikis as a tool for collaborative course management. Journal of Online Learning and Teaching, 4(2), 169-181.

Garramone, G. M., Harris, A. C. \& Anderson, R. (1986). Uses of political computer bulletin boards. Journal of Broadcasting \& Electronic Media, 30(3), 325-339. doi:10.1080/08838158609386627

Gefen, D., \& Straub, D. (2000). The relative importance of perceived ease of use in IS adaptation: A study of E-commerce adaptation. Journal of the Association for Information Systems, 1(8), 1-28.

Guo, Z. \& Stevens, K. J. (2011). Factors influencing perceived usefulness of wikis for group collaborative learning by first year students. Australasian Journal of Educational Technology, 27(2), 221-242.

Kang, M. J. \& Glassman, M. (2011) The logic of wikis: The possibilities of the Web 2.0 classroom. International Journal of Computer-Supported Collaborative Learning, 6 (1), 93-112. doi:10.1007/s11412-011-9107-y

Karahanna, E., \& Straub, D. W. (1998). The psychological origins of perceived usefulness and ease-of-use. Information \& Management, 35(4), 237-250. doi:10.1016/S0378-7206(98)00096-2

Kear, K., Woodthorpe, J., Robertson, S., \& Hutchison, M. (2010). From forums to wikis: Perspectives on tools for collaboration. Internet and Higher Education, 13(4), 218-225. doi:10.1016/j.iheduc.2010.05.004

Kim, J. (2013). Influence of group size on students' participation in online discussion forums. Computers \& Education, 62, 123-129. doi:10.1016/j.compedu.2012.10.025

Kim, S. S., \& Malhotra, N. K. (2005a). A longitudinal model of continued IS use: An integrative view of four mechanisms underlying post adaptation phenomena. Management Science, 51(5), 741-755. doi:10.1287/mnsc.1040.0326

Kim, S. S., \& Malhotra, N. K. (2005b). Predicting system usage from intention and past use: Scale issue in the predictors. Decision Sciences, 36(1), 187-196. doi:10.1111/j.1540-5915.2005.00070.x

Kimmerle, J., Moskaliuk, J., \& Cress, U. (2011). Using Wikis for learning and knowledge building: Results of an experimental study, Educational Technology \& Society, 14(4), 138-148.

Koschmann, T. (2002). Dewey's contribution to the foundations of CSCL research. In G. Stahl (Ed.), Computer support for collaborative learning: Foundations for a CSCL community (pp. 17-22). Mahwah, NJ: Lawrence Erlbaum Associates. doi:10.3115/1658616.1658618

Lee, J. W. (2010). Online support service quality, online learning acceptance, and student satisfaction. 
Internet and Higher Education, 13(4), 277-283. doi:10.1016/j.iheduc.2010.08.002

Liao, C., To, P. L., Liu, C. C., Kuo, P. Y., \& Chuang, S. H. (2011). Factors influencing the intended use of web portals. Online Information Review, 35(2), 237-254. doi:10.1108/14684521111128023

Maldonado, H., Lee, B., Klemmer, S. R., \& Pea, R. D. (2007). Patterns of collaboration in design courses: Team dynamics affect technology appropriation, artifact creation, and course performance. Proceedings of the 8th International Conference on Computer Supported Collaborative Learning, 490-499. doi:10.3115/1599600.1599690

Maldonado, U. P. T., Khan, G. F., Moon, J. \& Rho, J. J. (2009). E-learning motivation and educational portal acceptance in developing countries. Online Information Review, 35(1), 66-85. doi:10.1108/14684521111113597

Mercier, E. M., Booker, A., \& Goldman, S. (2003). Bringing collaboration front and center in a cross-disciplinary design course. Proceedings of World Conference on Educational Multimedia, Hypermedia and Telecommunications (pp. 4895-4900). Norfolk, VA: AACE,.

Meyer, K. A. (2010). A comparison of Web 2.0 tools in a doctoral course. Internet and Higher Education, 13(4), 226-232. doi:10.1016/j.iheduc.2010.02.002

Noël, S., \& Robert, J. M. (2003). Empirical study on collaborative writing: What do co-authors do, use, and like? Computer Supported Cooperative Work, 13(1), 63-89. doi:10.1023/B:COSU.0000014876.96003.be

Ong, C.-S., \& Lai, J.-Y. (2006). Gender differences in perceptions and relationships among dominants of e-learning acceptance. Computers in Human Behavior, 22(5), 816-829. doi:10.1016/j.chb.2004.03.006

O'Reilly, T. (2000). What is Web 2.0? Retrieved from http://oreilly.com/

Parker, K. R., \& Chao, J. T. (2007). Wiki as a teaching tool. Interdisciplinary Journal of Knowledge and Learning Objects, 3, 58-71.

Rice, R. E., Grant, A. E., Schmitz, J. \& Torobin, J. (1990). Individual and network influences on the adaptation and perceived outcomes of electronic messaging. Social Networks, 12(2), 27-55. doi:10.1016/0378-8733(90)90021-Z

Robey, D. (1979). User attitudes and management information system use. The Academy of Management Journal, 22(3), 527-538. doi:10.2307/255742

Saad, R., \& Bahli, B. (2005). The impact of cognitive absorption on perceived usefulness and perceived ease of use in on-line learning: An extension of the technology acceptance model. Information \& Management, 42(2), 317-327. doi:10.1016/j.im.2003.12.013

Schmitz, J., \& Fulk, J. (1991). Organizational colleagues, media richness, and electronic mail: A test of the social influence model of technology use. Communication Research, 18(4), 487-523. doi:10.1177/009365091018004003

Stahl, G. (2005). Group cognition in computer-assisted collaborative learning. Journal of Computer Assisted Learning, 21(2), 79-90. doi:10.1111/j.1365-2729.2005.00115.x

Stahl, G., Koschmann, T., \& Suthers, D. (2006). Computer-supported collaborative learning: An historical perspective. In R. K. Sawyer (Ed.), Cambridge Handbook of the Learning Sciences (pp. 409-426). Cambridge, UK: Cambridge University Press. doi:10.1007/s11412-006-9004-y

Suchman, L. A. (1995). Making work visible. Communications of the ACM, 38(9), 56-64. doi:10.1145/223248.223263

Suthers, D. (2006). Technology affordances for intersubjective meaning making: A research agenda for CSCL. International Journal of Computer-Supported Collaborative Learning, 1(3), 315-337. doi:10.1007/s11412-006-9660-y

Tsinakos, A. A. (2006). Collaborative student modeling- a new perspective using wiki. WSEAS Transactions on Advances in Engineering Education, 6(13), 475-481.

Venkatesh, V. (2000). Determinants of perceived ease of use: Integrating control, intrinsic motivation, and emotion into the technology acceptance model. Information Systems Research, 11(4), 342-365. doi:10.1287/isre.11.4.342.11872

Venkatesh, V., Morris, M. G., Davis, G. B., \& Davis, F. D. (2003). Use acceptance of information technology: Toward a unified view. MIS Quarterly, 27(3), 425-478.

Wei, C., Maust, B., Barrick, J., Cuddihy, E., \& Spyridaki, J. H. (2005). Wikis for supporting distributed collaborative writing. Proceedings of the Annual Conference of the Society for Technical Communication, 204-209.

Wever, B. D., Keer, H. V., Schellens, T., \& Valcke, M. (2011). Assessing collaboration in a wiki: The reliability of university students' peer assessment. Internet and Higher Education, 14(4), 201-206. doi:10.1016/j.iheduc.2011.07.003

Xiao, Y., \& Lucking, R. (2008). The impact of two types of peer assessment on students' performance and 
Australasian Journal of Educational Technology, 2015, 31(1).

satisfaction within a Wiki environment. Internet and Higher Education, 1(3-4), 186-193. doi:10.1016/j.iheduc.2008.06.005

Yeh, N. C., Lin, J. C. C., \& Lu, H. P. (2011). The moderating effect of social roles on user behavior in virtual worlds. Online Information Review, 35(5), 747-769. doi:10.1145/1330311.1330324

Yueh, H-P., \& Hsu, S. (2008). Designing a learning management system to support instruction. Communications of the ACM, 51(4), 59-63.

Yueh, H-P., Lin, W., Liu, Y. L., Shoji, T., \& Minoh, M. (2014). The development of an interaction support system for international distance education. IEEE Transactions on Learning Technology, 7(2), 191-196. doi:10.1109/TLT.2014.2308952

Corresponding author: Hsiu-Ping Yueh, yueh@ntu.edu.tw

Australasian Journal of Educational Technology (c) 2015.

Please cite as: Yueh, H-P., Huang, J-Y., \& Chang, C. (2015). Exploring factors affecting students' continued Wiki use for individual and collaborative learning: An extended UTAUT perspective. Australasian Journal of Educational Technology, 31(1), 16-31. 